\title{
"Kelulut" stingless bee culture of Datai Lino farmer group in Bentian Besar Village, Kutai Barat, Indonesia
}

\author{
Syafrizal $^{\# 1}$, Rudy Agung Nugroho ${ }^{\# 2}$, Rudianto ${ }^{\# 2}$, Widha Prahastika ${ }^{\# 2}$ \\ ${ }^{1}$ Laboratorium Sistematika dan Ekologi Tumbuhan, Jurusan Biologi, Fakultas Matematika dan Ilmu Pengetahuan Alam \\ Universitas Mulawarman, Samarinda, Kalimantan Timur \\ ${ }^{2}$,Laboratorium Fisiologi, Perkembangan dan Molekuler Hewan, Jurusan Biologi, Fakultas Matematika dan Ilmu Pengetahuan \\ Alam Universitas Mulawarman, Samarinda, Kalimantan Timur \\ * Correspondence: rudyagung.nugroho@ fmipa.unmul.ac.id; Tel.: +6281283088955
}

Diterima 21 Juli 2019, Disetujui 25 November 2019 Dipublikasikan 30 November 2019

\begin{abstract}
A Community service program known as Program Kemitraan Masyarakat (PKM) was done from April-July 2019 at Bentian Besar village, Bentian Kutai Barat, Kalimantan Timur. The purpose of the PKM was to empower community, especially Datai lino farmer group in order to enhance their productivity and transfer Science and technology, assisting the member of Datai lino farmer group to do stingless bee culture. In this program, the member of farmer group has obtained a soft skill and an experience in stingless bee culture. Further, this program can empower the member of Datai lino farmer to be an entrepreneurship, providing stingless bee product such as propolis and honey bee which has an economic value. This program was done in two sections, theory and practice with ratio 25\%:75\%. In theory section, the member of PKM has delivered a presentation regarding stingless bee culture technique. In the practice section, the members of datai lino farmer group directly built stingless bee home base and applied stingless bee culture, including maintenance bee colony and harvest the products. The outcome of the PKM program was soft skill transfer technology, a stingless bee culture module. In the future, this program can be implemented to boost the economic value for the members of Datai lino farmer group in Bentian, Kutai Barat, Kalimantan Timur.
\end{abstract}

Keywords - Community empowerment, Stingless bee, Datai Lino, Bentian village, Kutai Barat

This is an open access article distributed under the Creative Commons 4.0 Attribution License, which permits unrestricted use, distribution, and reproduction in any medium, provided the original work is properly cited. (C2017 by author and Universitas Negeri Padang.

\section{Pendahuluan}

Kabupaten Kutai Barat berada pada koordinat $113^{\circ} 45^{\prime} 05^{\prime \prime}-116^{\circ} 31^{\prime} 19^{\prime \prime}$ BT dan diantara $1^{\circ}$ 31' 35" LU and $1^{\circ} 10^{\prime}$ ' 16" LS. Total luasan kabupaten ini mencapai $31,629 \mathrm{~km} 2$, berada pada ketinggian antara $0-1500 \mathrm{~m}$ di atas permukaan laut (dpl) [1]. Potensi kawasan hutan dan tanah lahan di wilayah Kutai Barat sangatlah luas dan belum termanfaatkan dengan baik, terutama di wilayah Kampung Dilang Puti, kecamatan Bentian, Kutai Barat (Gambar 1).
Kecamatan Bentian Besar memiliki luas wilayah sekitar 886,4 $\mathrm{km}^{2}$ dengan jumlah penduduk 3.104 jiwa. Penduduk Bentian Besar sendiri terdiri dari beberapa suku atau etnis. Etnis

Bentian dan benuaq merupakan etnis yang dominan dan etnis yang lain adalah Kutai, Dayak, Bugis dan Jawa. Secara geografis Kecamatan Bentian Besar berada di wilayah Kabupaten Kutai Barat terletak pada $0^{0} 54^{\prime} 04$ 'S dan $115^{\circ} 42^{\prime} 33^{\prime \prime} \mathrm{E}$ dengan batas-batas sebagai berikut:

- Sebelah Utara dengan Kecamatan Muara Lawa. 
- Sebelah Timur dengan Kecamatan Muara Pahu.

- Sebelah Selatan dengan Provinsi Kalimantan Tengah.

- Sebelah Barat dengan Kecamatan Damai.

Kecamatan Bentian Besar saat ini memiliki 9 Desa yakni Desa Dilang Puti, Desa Anan Jaya, Desa Jelmu Sibaq, Desa Penarung, Desa Randa

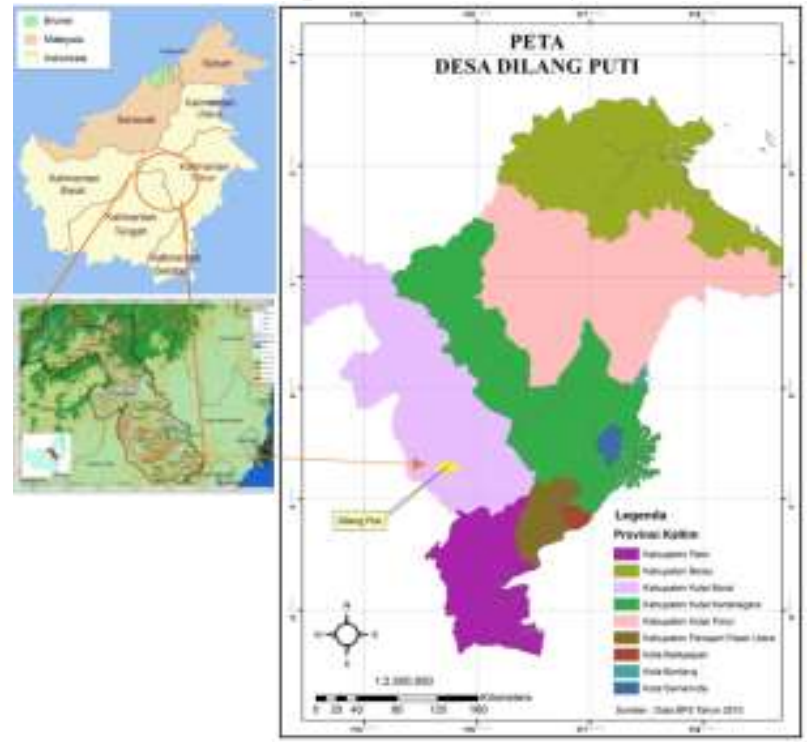

Gambar 1. Peta lokasi Kampung Dilang Puti, Desa Bentian Besar, Kutai Barat

Empas, Desa Sambung, Desa Suakong, Desa Tende dan Desa Tukuq. Mata pencaharian utama sebagian besar penduduknya adalah sebagai petani dengan kegiatan budidaya berbagai jenis tanaman meliputi padi sawah dan padi ladang, 6 jenis tanaman palawija, 10 jenis tanaman sayur-sayuran, 19 jenis tanaman buah-buahan (Gambar 2). Di samping itu juga terdapat kegiatan budidaya 7 jenis ternak, serta budidaya dan penangkapan ikan. Usaha lain yang berkembang adalah usaha pengolahan hasil hutan kayu dan non kayu.
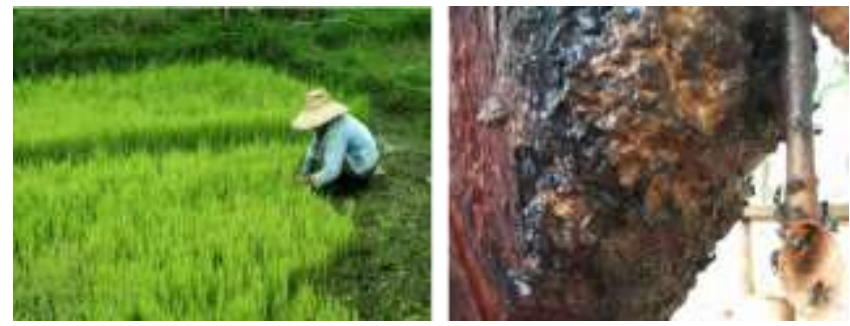

Gambar 2. Pertanian di Kutai barat (kiri). Potensi lebah kelulut untuk dibudidayakan (Kanan)
Dari hasil jajak komunikasi dengan Pemuka adat di kampung dan ketua kelompok tani Datai Lino, para petani ternyata merupakan tipe petani pasif, musiman dan hanya bertani hanya untuk kebutuhannya sendiri atau untuk konsumsi sendiri. Dengan demikian masyarakat petani di wilayah tersebut merupakan kategori masyarakat tani yang non produktif.

Selain non produktif, masyarakat tani tersebut tidak menyadari bahwa ada potensi alam yang tersedia di sekitar tempat tersebut yang dapat dikembangkan menjadi hal yang produktif dan menjadi tambahan pemasukan bagi masyarakat sekitar, yaitu potensi lebah kelulut sebagai penghasil madu dan propolis. Menurut penelitian yang telah dilakukan sebelumnya, kelulut merupakan lebah yang berpotensi menghasilkan propolis [2] dan berpotensi untuk dibudidayakan serta dikembangkan untuk menambah penghasilan di kalangan masyarakat.

Saat ini kelompok tani Datai Lino telah mengadakan kerjasama dengan Yayasan Khatulistiwa Indonesia (Yasiwa), yang juga memfasilitasi kegiatan konservasi. Namun untuk kegiatan yang terkait budidaya lebah kelulut belum diawali dan dilaksanakan karena belum adanya pembimbingan dan pengarahan dari tenaga ahli atau peneliti dari perguruan tinggi. Untuk itulah, program pengabdian masyarakat ini dibuat untuk menjembatani kekosongan kemitraan antara peneliti dari perguruan tinggi dan masyarakat, terkhusus dalam menangkap peluang usaha dan berbisnis dibidang budidaya lebah kelulut, terutama transfer teknologi budidaya kelulut untuk meningkatkan perekonomian dengan hasil madu dan propolisnya.

\section{Solusi/Teknologi}

Mengingat kondisi perekonomian yang perlu ditingkatkan, potensi adanya lebah kelulut yang ada dan antusiasme masyarakat dalam bidang budidaya lebah kelulut, maka perlu adanya kegiatan pemberdayaan masyarakat. Lebih spesifik lagi, kelompok tani yang tinggal di Bentian, Kutai Barat melakukan kegiatan pertanian hanya untuk konsumtif/non produktif, potensi lebah kelulut belum termanfaatkan 
dengan baik. Hal tersebut merupakan masalah sosial ekonomi dan menimbulkan masalah tidak adanya peningkatan nilai perekonomian rakyat, padahal mempunyai potensi adanya lebah kelulut yang dapat dibudidayakan dan meningkatkan perekonomian petani tersebut. Program pengabdian pada masyarakat ini mencoba memberikan aplikasi praktis budidaya lebah kelulut dengan cara, pembekalan soft skill kepada beberapa masyarakat tani Datai Lino, Bentian besar, Kutai Barat yang tergabung dalam kelompok tani Datai Lino untuk dapat menerapkan teknik budidaya lebah kelulut. Sementara itu mitra Yasiwa, berperanan dalam penyediaan lahan untuk praktek dan akan membantu menjembatani kelompok tani dalam promosi hasil budidaya lebah, yaitu madu dan propolis kepada konsumen sehingga dari hulu ke hilir manfaat dari program pengabdian pada masyarakat ini dapat terwujud, dan berguna bagi peningkatan ekonomi kerakyatan.

Program pengabdian ini bertujuan untuk mengenalkan teknik budidaya lebah kelulut kepada kelompok tani Datai Lino, Bentian, Kutai Barat, serta membimbing anggota kelompok tani tersebut supaya bisa melakukannya secara mandiri, terampil dan tepat cara budidaya lebah kelulut. Dengan program pengabdian ini tiap anggota kelompok tani Datai Lino akan memiliki soft skill dan pengalaman di bidang budidaya lebah kelulut. Pada akhirnya anggota kelompok tani Datai Lino tersebut diharapkan dapat memanfaatkan teknologi ini untuk meningkatkan perekonomian mereka.

Adapun luaran kegiatan ini adalah pembekalan softskill/metode kepada para anggota kelompok tani Datai Lino, kelompok tani tersebut mempunyai tempat percontohan dan model budidaya lebah kelulut. Di samping itu hasil praktek langsung budidaya lebah kelulut yang telah dilakukan anggota kelompok tani berupa bibit kelulut, madu dan propolis dapat dimanfaatkan untuk kelanjutan usaha budidaya berikutnya.

Dalam rangka mengatasi masalah yang terjadi di wilayah pengabdian yaitu adanya potensi lebah kelulut yang belum termanfaatkan dan masyarakat tani yang tidak produktif, maka kegiatan ini menjadi solusi untuk memecahkan masalah tersebut dengan cara budidaya lebah kelulut. Secara garis besar pelaksanaan program pengabdian ini dilaksanakan dalam dua metode besar yaitu teori dan praktek dengan perbandingan $1 \mathrm{x}$ teori dan $2 \mathrm{x}$ praktek pembimbingan, pembuatan dan praktek budidaya lebah kelulut.

\section{Pendampingan teori}

Tim pengabdian masyarakat akan memberikan gambaran teori sekilas mengenai lebah kelulut, yang sebelumnya telah dilakukan penelitian dan telah diterbitkan dalam artikel jurnal [3] [4]. Teori ini juga menyangkut mengenai aspek penanganan hasil produk budidaya lebah kelulut. Di dalam teori ini kelompok mitra tani Datai Lino, Bentian akan dikumpulkan dalam satu tempat di kamp yasiwa (Mitra pelaksana, surat kesediaan terlampir), Bentian besar untuk diberikan penjelasan secara teori tentang gambaran program. Metode penyampaian adalah dengan cara presentasi, diskusi dan tanya jawab.

2. Pendampingan praktek

Tim pengabdian pada masyarakat akan memberikan secara langsung (transfer soft skill) dan pendampingan kepada kelompok tani Datai Lino (15an orang) mengenai teknik budidaya lebah kelulut hingga penggunaannya. Di bagian akhir juga praktek akan dilakukan evaluasi program.

\section{Teknis pelaksanaan}

Dalam teknis pelaksanaan, tim pengabdian masyarakat akan mendata kembali anggota kelompok tani Datai Lino yang akan mengikuti pembimbingan dan pendampingan program pengabdian pada masyarakat ini. Sementara itu, Mitra pelaksana (Yasiwa), akan mempersiapkan tempat/lahan baik untuk pertemuan dan pendampingan pertama yang bersifat teori (Kelas) dan pertemuan dan pendampingan selanjutnya yang bersifat praktek. Dalam praktek program pengabdian pada masyarakat ini, mitra pelaksana (Yasiwa) akan mempersiapkan lahan untuk keperluan praktek, pembuatan tenda untuk tempat praktek dan juga menjembatani hasil budidaya lebah kelulut (Madu dan propolis) untuk disalurkan kepada konsumen yang membutuhkan. 
Dalam pembudidayaan lebah madu kelulut yang perlu dipersiapkan yaitu: Lokasi budidaya, kandang lebah modern (stup), pakaian kerja dan peralatan Syarat yang utama yang harus yang dipenuhi dalam budidaya lebah adalah ada seekor ratu lebah dan ribuan ekor lebah pekerja serta lebah jantan. Dalam satu koloni tidak boleh lebih dari satu ratu karena antar ratu akan saling bunuh untuk memimpin koloni.

\section{Hasil dan Diskusi}

Kegiatan PKM ini telah dilaksanakan di desa Bentian, Kutai Barat, Kalimantan Timur. Akses menuju desa Bentian dari kota Samarinda sekitar 6.5 jam perjalanan darat. Mitra kegiatan PKM ini adalah kelompok tani Datai lino, Bentian. Kelompok tani Datai lino di lokasi PKM melaksanakan kegiatan harian bertani, sementara mitra kegiatan PKM yaitu yayasan katulistiwa Indonesia (Yasiwa) mendukung kegiatan dalam hal komunikasi dengan warga tani serta manajemen kegiatan PKM.

Kegiatan PKM ini dimulai dengan diskusi pelaksanaan program dengan pihak-pihak terkait, mitra dan melakukan perencanaan pelaksanaan kegiatan (Gambar 3a). Setelah semuanya terencana dengan baik, kegiatan berikutnya yaitu berupa penyuluhan (Pengetahuan teori) mengenai budidaya kelulut (Gambar 3b). Ada sekitar 15-an anggota kelompok tani datai lino yang menghadiri acara ini (Gambar 3c). Setelah acara penyuluhan dilanjutkan dengan sessi tanya jawab mengenai budidaya kelulut. Kegiatan kemudian dilanjutkan dengan praktek budidaya kelulut (Gambar 3d).
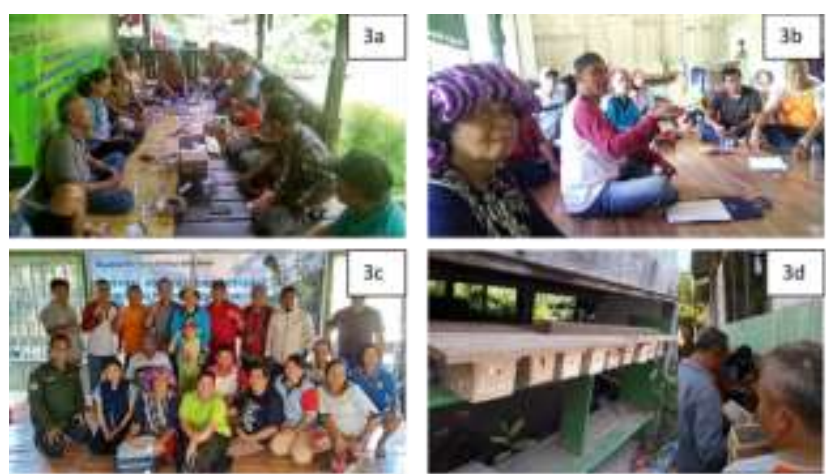

Gambar 3. Bincang-bincang, persiapan kegiatan dengan mitra dan masyarakat sasaran, kegiatan sesi teori dan praktek a. Persiapan kegiatan PKM budidaya kelulut

Kegiatan

persiapan

"brainstorming"

pengabdian program kemitraan masyarakat (PKM) ini dilangsungkan bersama mitra Yasiwa membahas seputar rangkaian kegiatan pengabdian. Persiapan kegiatan PKM juga didiskusikan dengna pihak aparat (Kepala desa Bentian) untuk menggali lebih dalam permasalahan dan solusi seputar masyarakat tani Bentian.

Penyiapan Sarana dan Peralatan

Perkandangan

a. Suhu

Perubahan suhu dalam stup hendaknya tidak terlalu cepat, oleh karena itu ketebalan dinding perlu diperhatikan untuk menjaga agar suhu dalam stup tetap stabil. Yang umum digunakan adalah kayu empuk setebal 2,5 cm.

b. Ketahanan terhadap iklim

Bahan yang dipakai harus tahan terhadap pengaruh hujan, panas, cuaca yang selalu berubah, kokoh dan tidak mudah hancur atau rusak.

c. Konstruksi

Konstruksi kandang tradisional dengan menggunakan gelodok dari bambu, secara modern menggunakan stup kotak yang lengkap dengan framenya.

\section{Peralatan}

Peralatan yang digunakan dalam budidaya lebah terdiri dari: masker, pakaian kerja dan sarung tangan, pengasap, penyekat ratu, sangkar ratu, sapu dan sikat, tempat makan, pondamen sarang, alat-alat kecil, peralatan berternak ratu dan lain-lain.

\section{Teknik budidaya;}

\section{Metode Penanaman}

Penyiapan koloni budidaya secara langsung memindahkan koloni dari alam; baik yang berasal dari lubang kayu atau tanah, ke dalam kotak (stup) pemeliharaan.

2. metode Tempelan

Penyiapan koloni budidaya secara tidak langsung memindahkan bakalan koloni dari alam dengan cara menyambung/mengarahkan pintu 
masuk sarang (entrance) ke dalam kotak (stup) pemeliharaan.

3. metode Pemisahan

Penyiapan koloni budidaya secara langsung dengan memindahkan sebagian koloni dari kotak pemeliharaan yang telah ada ke dalam kotak (stup) pemeliharaan yang baru.

Berikut ini beberapa keistimewaan Kelulut dibanding lebah lainnya:

$>$ Tidak perlu peralatan khusus

Tidak perlu digembala/Tidak mengenal masa paceklik

Tidak perlu takut disengat

Kemudahan dalam pengembangan koloni

Produktivitas propolis lebih tinggi

Pemeliharaan

Sanitasi, Tindakan Preventif dan Perawatan

Pada pengelolaan lebah secara modern lebah ditempatkan pada kandang berupa kotak yang biasa disebut stup. Di dalam stup terdapat ruang untuk beberapa frame atau sisiran. Dengan sistem ini peternak dapat harus rajin memeriksa, menjaga dan membersihkan bagian-bagian stup seperti membersihkan dasar stup dari kotoran yang ada, mencegah semut/serangga masuk dengan memberi tatakan air di kaki stup dan mencegah masuknya binatang pengganggu.

\section{Pengontrolan Penyakit}

Pengontrolan ini meliputi menyingkirkan lebah dan sisiran sarang abnormal serta menjaga kebersihan stup.

\section{Tindak lanjut budidaya kelulut}

Untuk lebih memantapkan dan keberlanjutan program PKM ini, Kelompok tani Datai Lino dengan inisiatif Kelompok dan disertai dengan keinginan untuk mengembangkan budidaya kelulut ini, maka terbentuklah Kelompok budidaya kelulut (Gambar 4). Kelompok ini juga terus mendapatkan bimbingan dan pengawasan dari mitra Universitas agar program tetap berjalan dan mendapatkan hasil/produk dan dapat dikembangkan jauh lebih besar.

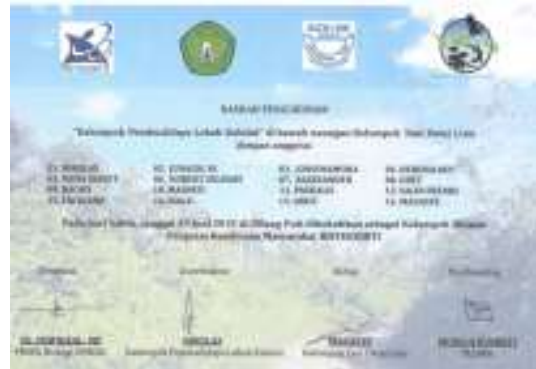

Gambar 4. Sertifikat pengukuhan kelompok budidaya lebah kelulut Datai lino

\section{Kesimpulan}

Program kemitraan masyarakat telah dilaksanakan dengan baik dan melibatkan Pengabdi dan masyarakat Bentian, Kutai Barat. Kegiatan dimulai perencanaan program, penyuluhan/teori dan praktek budidaya kelulut. Capaian kegiatan untuk memberdayakan masyarakat Bentian, Kutai Barat agar dapat makin produktif melalui budidaya kelulut. Di samping itu adalah adanya transfer pengetahuan budidaya kelulut secara nyata dibuktikan dengan anggota kelompok masyarakat Bentian dapat memelihara lebah kelulut, dan memperbanyak lebah kelulut. Berdasarkan respon dari peserta program PKM ini menyebutkan bahwa kegiatan ini sangat bermanfaat dan menjadi pemberdayaan warga. Keberlanjutan kegiatan ini ditandai dengan terbentuknya pembudidaya lebah kelulut dan mendapatkan pembinaan serta pengawasan dari pelaksana program PKM Universitas Mulawarman.

Disarankan agar ada program pengabdian yang mendukung budidaya kelulut, seperti teknologi pasca panen, dan pengolahan produk-produk kelulut misal untuk dijadikan bahan obat. Program PKM ini juga bisa dilanjutkan untuk daerah-daerah lain yang masih sangat memerlukan introduksi teknologi dan pendampingan dari Perguruan Tinggi.

\section{Ucapan Terima Kasih}

Seluruh anggota tim Program Kemitraan masyarakat (PKM) Pengabdian kepada Masyarakat mengucapkan terima kasih kepada Kemenristekdikti atas sponsor dana hibah dalam kegiatan ini melalui kontrak no: 227/UN17.41/KT/2019 Tahun Anggaran 2019. 
Tim juga mengucapkan terima kasih kepada LP2M Universitas Mulawarman, FMIPA, Universitas Mulawarman, Samarinda yang telah mendukung terlaksananya kegiatan ini. Tak lupa kepada, kelompok tani Datai Lino, Yayasan Khatulistiwa (Yasiwa) Ibu Monika Kiki, S.Si., Nur Linda Isa, S.Si., PUI PT OKTAL Universitas Mulawarman, dan semua civitas Universitas Mulawarman yang telah mendukung terlaksananya kegiatan ini.

\section{Pustaka}

[1] Arrami M, Garner H. A tale of two citations. Nature. 2008; 451(7177): 397-399.

[2] Watkins PJ. $A B C$ of Diabetes. 5th ed. London: Blackwell Publishing; 2003.

[3] Simons NE, Menzies B, Matthews M. A Short Course in Soil and Rock Slope Engineering. London: Thomas Telford Publishing; 2001.

[4] Goldacre B. Dore - the media's miracle cure for dyslexia. Bad Science. Weblog. Available from: http://www.badscience.net/2008/05/dore-themedias-miracle-cure-for-dyslexia/\#more-705 [Accessed 19th June 2015]. 